Article Type: Review

\title{
Food allergy in EAACI journals (2016)
}

\author{
Ulrich Wahn ${ }^{1}$, Paolo M Matricardi ${ }^{2}$, Thomas Bieber ${ }^{3}$, Jean Bousquet ${ }^{4,5}$, Clive Grattan ${ }^{6}$, Hans-Uwe \\ Simon ${ }^{7}$, Antonella Muraro ${ }^{8}$, loana Agache ${ }^{9}$
}

1. Pediatric Department, Charité, Berlin, Germany.

2. AG Molecular Allergology and Immunomodulation, Department of Pediatric Pneumology and Immunology, Charité Medical University, Berlin, Germany.

3. Department of Dermatology and Allergy, Rheinische Friedrich-Wilhelms-University Bonn, Bonn, Germany

4. MACVIA-France, Contre les MAladies Chroniques pour un VIeillissement Actif en France European Innovation Partnership on Active and Healthy Ageing Reference Site, Montpellier, France.

5. INSERM U 1168, VIMA : Ageing and chronic diseases Epidemiological and public health approaches, Villejuif, Université Versailles St-Quentin-en-Yvelines, UMR-S 1168, Montigny le Bretonneux, France and Euforea, Brussels, Belgium

6. Dermatology Centre, Norfolk \& Norwich University Hospital, Norwich, United Kingdom.

7. Institute of Pharmacology, University of Bern, Bern, Switzerland.

8. Food Allergy Referral Centre Veneto Region, Department of Women and Child Health, Padua General University Hospital, Padua, Italy.

9. Faculty of Medicine, Transylvania University, Brasov, Romania.

\section{Corresponding author:}

Professor Ulrich Wahn

Pediatric Department, Charité, Berlin, Germany

Ulrich.Wahn@charite.de

\section{Short title: EAACI papers in food allergy}

Key words: Allergy, diagnosis, EAACI, food, prevention, treatment

\section{Introduction}

The European Academy of Allergy and Clinical Immunology (EAACI) owns three journals: Allergy, Pediatric Allergy and Immunology and Clinical and Translational Allergy. One of the major goals of EAACI is to understand and better manage food allergy, and to disseminate the knowledge of allergy to all stakeholders including the EAACI junior members (1). The European Symposium on Precision Medicine in Allergy and Airways Diseases at the European Union Parliament (October 14, 2015) stressed that the socioeconomic impact of food allergy (2).

This article has been accepted for publication and undergone full peer review but has not been through the copyediting, typesetting, pagination and proofreading process, which may lead to differences between this version and the Version of Record. Please cite this article as doi: $10.1111 /$ pai.12830

This article is protected by copyright. All rights reserved. 
Several papers of the EAACI journals have dealt with food allergy in 2016. The current paper summarises the achievements made by the publications.

\section{Animal models}

The introduction of new protein sources into the diet may create new food allergies that, if possible, should be predicted. Robust and reliable animal models would be valuable tools for safety assessment, but, to date, none have been formally validated as predictive and none are currently suitable to test the allergenic potential of new foods (3). Maternal exposure to GOS/inulin mixture prevents food allergies and promotes tolerance in offspring in mice (4)

\section{Allergens}

New allergens have been published. Fish collagen is an important panallergen in the Japanese population (5).

Cross reactivities are an important research field. Birch-sensitized individuals are frequently cosensitized to hazelnut, almond, and peanut. Among the birch-negatives, prevalence of nut sensitizations decreases from early childhood to adolescence. Cashew and pistachio, and pecan and walnut cross-react the most (6). IgE to novel citrus seed allergens was found among cashew-allergic children (7). Cross-reactivity to fish and chicken meat has been discovered suggesting a new clinical syndrome with cross-reactive allergens involved being parvalbumins, enolases, and aldolases (8).

Modification of allergens is another important topic to attempt to reduce allergenicity. Hydrolysed egg displays strong decrease in allergenicity and is well tolerated by egg-allergic patients (9). Children with IgE-mediated egg allergy often tolerate baked egg within a wheat matrix (10). Very strict standardized cooking procedures do not seem to be essential, to guarantee tolerance toward baked eggs.

\section{Mechanisms}

Endotypes of pollen-food syndrome in 1271 Italian children (age 4-18 years) with seasonal AR were studied using a molecular classification (11) Pollen-food syndrome is a complex and frequent complication of AR, with five distinct endotypes marked by peculiar profiles of IgE sensitization to panallergens.

Indoleamine 2,3-dioxygenase (IDO), which degrades tryptophan to kynurenine, may contribute to modulation of allergic responses. There is a low IDO activity in persistent food allergy in children (12). These results suggest the involvement of IDO in development of tolerance process, and high IDO activity may be associated with nonresponsiveness to food allergens despite allergen sensitization.

Ingestion of food allergens present in maternal milk during breastfeeding has been hypothesized as a gateway to sensitization to food. However, this process could develop during pregnancy. The detection of major food allergens in all amniotic fluid samples studied indicates an initial allergenic encounter during pregnancy (13).

This article is protected by copyright. All rights reserved. 


\section{Cow's milk allergy}

Cow's milk allergy (CMA) is the most common allergic disease in infancy but it is not clear whether infants with CMA have an increased risk of developing other allergic diseases later in life. The study assessed genetic associations of CMA using reported single nucleotide polymorphisms (SNP) in other allergic diseases and genetic mutations within the FLG gene in 30 children from the Dutch EuroPrevall birth cohort study (14). Two SNPs with CMA were reported suggesting that variation in the TLR6 and IL2 genes contribute to the expression of CMA. In addition, since TLR6 and IL2 were earlier associated with other later onset allergies, this also favours the "allergic march" hypothesis.

Consumption of unboiled farm milk in early life prevents the development of atopic diseases. Milk is a complex signalling and epigenetic imprinting network that promotes stable FoxP3 expression and long-lasting Treg differentiation, crucial postnatal events preventing atopic and autoimmune diseases (15).

Optimally hydrolyzed beta-Lactoglobulin ( $(\mathrm{Lg}$ ) is a promising milk oral immunotherapy (OIT) candidate with reduced B-cell reactivity but retaining the T-cell epitope. Chymotrypsin affected the retention of the T-cell epitope of $B \mathrm{Lg}$ when preparing $\beta \mathrm{Lg}$ hydrolysates using food-grade trypsin. Chymotrypsin activity inhibited the formation of $\beta \mathrm{Lg} 102-124$ in the trypsin hydrolysate of $\beta \mathrm{Lg}$ showing that it is a novel candidate for peptide-based CMA OIT (16). However, immediate hypersensitivity to extensively hydrolyzed formulas can be observed (17)

Breastfeeding may induce allergic sensitization to peanut. In 32 lactating, non-peanut-allergic women peanut consumption induced detectable Ara h2, the most potent peanut allergen, in nine subjects. Time and concentration of secreted Ara h 2 in breast milk appears to be individually regulated. (18).

Breastmilk fatty acids have been associated with childhood allergic disease. Children of families with an anthroposophic lifestyle have a low prevalence of sensitization. In the ALADDIN birth cohort (19) a higher concentration of omega-3 PUFAs in breastmilk may be associated with a reduced risk of sensitization up to 24 months of age. However, this did not explain the lower risk of sensitization among children of anthroposophic families.

CMA in infancy is associated with subsequent development of asthma and pediatric inflammatory bowel disease (20). This suggests that in a subgroup of patients, CMA may share underlying background with pediatric inflammatory bowel disease, warranting thorough follow-up.

Impaired health-related quality of life (HRQL) was found in adolescents with allergy to staple foods (Cow's milk, hen's egg and wheat) using the Swedish version of EuroPrevall's disease-specific food allergy quality of life questionnaire-teenager form (FAQLQ-TF) (21). The number and type of previous symptoms and history of anaphylaxis were not associated with worse HRQL.

Nutritional adequacy of a cows' milk exclusion diet in infancy is a matter of concern. In the crosssectional study of 8- to 27-month-old children from the Isle of Wight, children consuming an exclusion diet for cows' milk allergy have an overall less varied diet, including a less varied consumption of meat and sweet foods (22). Efforts should be made to ensure exclusion diets are as varied as possible to optimize nutritional intake. A study assessed the nutritional adequacy of a cows' milk exclusion diet in a group of UK infants (subgroup of the Prevalence of Infant Food Allergy study) over 6 months (23). Although infants consuming a milk-free diet have a nutritional intake

This article is protected by copyright. All rights reserved. 
significantly different to matched controls who are eating an unrestricted diet, this difference is not constant and it is not seen for all nutrients.

\section{Epidemiology}

Data are lacking regarding the prevalence of food sensitization and probable food allergy among general population in India. The prevalence of food sensitization and probable food allergy among adults in India was studied by the EuroPrevall INCO study (24). A high level of sensitization (26.5\%) was observed by questionnaire for most of the foods in the general population, higher than that observed among adults in Europe, except for those foods that cross-react with birch pollen. Most of the sensitization was observed in subjects who had total IgE above the median IgE level. However, the prevalence of probable food allergy (self-reports of adverse symptoms after the consumption of food and specific IgE to the same food) was very low (1.2\%).

Patients often report adverse reactions to wheat. However, a very low prevalence of $\operatorname{IgE}$ mediated wheat allergy and high levels of cross-sensitisation between grass and wheat were found in the UK Food Allergy and Intolerance Research (FAIR) birth cohort (25).

Prevalence, incidence and natural history of food hypersensitivity and its trends were tested in the Isle of Wight (UK) birth cohort. By the age of 10 years, 6.8\% of children suffered from food hypersensitivity based on food challenges and a good clinical history. There was a large discrepancy between reported and diagnosed food hypersensitivity.

Kiwifruit is a common cause of food allergy but population-based studies concerning the prevalence of kiwifruit allergy are lacking. The prevalence and clinical characteristics of IgE-mediated kiwifruit allergy in 6-18-year-old urban schoolchildren were tested in a region where kiwifruit is widely cultivated. All children with a positive SPT to kiwifruit were invited for an open OFC (26) The estimated prevalence of IgE-mediated kiwifruit allergy was very low $(0.5 \%)$.

Egg sensitization, allergy and component patterns are poorly determined in African children with AD. A prospective, observational study in a paediatric university hospital in Cape Town found that the prevalence of egg allergy is high in African children with $\mathrm{AD}$, but history of egg allergy and sensitization to egg significantly overestimate the true egg allergy rate. The component ovomucoid was useful for differentiating allergy from tolerance in egg-sensitized participants (27).

Thee are ethnic differences in prevalence of cashew nut, pistachio nut and almond allergy (28).

Children with asthma, hay fever, and food allergy may have several factors that increase their risk of speech disorder, including allergic inflammation, attention deficit hyperactivity disorder and sleep disturbance. A cross-sectional data on 337,285 children aged 2-17 years from 19 US population-based studies showed that asthma, hay fever, and food allergy are associated with caregiver-reported speech disorders in US children (29).

\section{Diagnosis}

\section{Component resolved diagnosis (CRD)}

Cor a 14 is the best serological marker for hazelnut allergy in children, independent of concomitant peanut allergy. Three independent and well-characterized serotypes were observed : hazelnut-allergic

This article is protected by copyright. All rights reserved. 
children were sensitized to Cor a 14, peanut-allergic children were sensitized to Ara $\mathrm{h} 2$, and independently of this were children sensitized to birch pollen (Bet v 1) (30).

Profilin sensitisation is a diagnostic confounding factor. A study assessed pollen sensitisation profiles in adults and children and to evaluate, by means of component-resolved diagnosis (CRD, ADVIACentaur) and skin prick testing (SPT) (31). In patients sensitised to profilin, the concordance between SPT and CRD is much lower than in those not sensitised to profilin. CRD is able to provide refined information about which pollens increase the risk of sensitisation to profilin.

\section{Food challenges}

Recombinant Mal d 1 facilitates sublingual challenge tests of birch pollen-allergic patients with apple allergy (32).

Multicentre trials investigating food allergies by double blind placebo controlled food challenges (DBPCFC) need standardized procedures, challenge meals and evaluation criteria. Standardization of DBPCFC with soy within a multicentre trial was carried out with microbiologically stable soy challenge meals composed of protein isolate with consistent Gly m 4 levels (33). Patients sensitized to main birch allergen Bet $\mathrm{v} 1$ and concomitant sensitization to its soy homologue Gly $\mathrm{m} 4$ underwent DBPCFC. 138 adults with Bet $\mathrm{v} 1$ and Gly $\mathrm{m} 4$ sensitization were investigated. It was found that the evaluation of DBPCFC outcome should not only include monitoring of objective signs but also scoring of subjective symptoms.

The time during which children are observed following a DBPCFC varies in clinical practice. A total of 1142 food-allergic children underwent DBPCFCs. 400 reported late reactions following the DBPCFC (34). Late reactions were poorly predictable and generally not severe. All late reactions, including those on the placebo day, are more frequently reported in younger children. Children who do not experience severe immediate reactions may be safely discharged home $2 \mathrm{~h}$ after a DBPCFC.

Specific IgE (sIgE) is often used to predict OFC outcomes in food allergy, but interpretation of the results may vary depending on the assay method employed and the patient population tested. A prospective multicenter study in Japan used two commercial assay systems to determine egg-sIgE values predictive of allergy within the most common populations treated at pediatric clinics (35). Cutoff values and probability curves for egg-sIgE were established using both ImmunoCAP and IMMULITE((R)) 20003 gAllergy.

Previous studies showed that HRQL significantly improved after the food challenge, with greater improvements in HRQL after a negative outcome than after a positive outcome. However, a study in 112 children found no difference in HRQL after a food challenge with cashew nut in children participating in a clinical trial (36).

\section{Basophil activation test}

The basophil activation test may provide information to better distinguish between sensitized and allergic subjects. CD203c expression displayed a better discrimination compared to CD63 (37). Oral food challenge is the gold-standard to diagnose food allergy but it is time consuming and may potentially elicit severe reactions. The basophil activation test has emerged as a new diagnostic test for food allergy (38). Exploratory analysis of CD63 and CD203c expression in basophils from hazelnut sensitized and allergic individuals were used to investigate basophil activation profiles (39).

This article is protected by copyright. All rights reserved. 
CD63 and CD203c expression differed between allergic (oral allergy syndrome and systemic group) and sensitized subjects.

\section{Eosinophilic gastroenteritis}

Eosinophilic esophagitis (EoE) is a severe inflammatory disease of the esophagus which is characterized histologically by an eosinophilic infiltration into the esophageal tissue. The efficacy of probiotics in the context of atopic diseases has been well investigated but, to date, there has been no study which has evaluated probiotic effects on EoE inflammation. The beneficial effect of Lactococcus lactis NCC 2287 was found in a murine model of EoE. (40).

A dysbiotic gut microbiome may play an important role in the development of allergic diseases. Genetic, environmental, and dietary factors may alter the commensal microbiota leading to inflammatory dysregulation of homeostasis. Murine and human studies have begun to elucidate the role of the microbiota in the pathogenesis of atopic diseases including asthma, atopic dermatitis, and food allergies. The role of the microbiome in EoE was reviewed (41).

A new EoE-like disease without tissue eosinophilia was found in EoE families (42). Patients suffering from 'EoE without eosinophilia' do not fulfill formally the diagnostic criteria for EoE. However, their clinical manifestation, immunohistology, and gene expression pattern and the transmission of the disease in the family suggest a uniform underlying pathogenesis.

EoE is frequently associated with concomitant atopic diseases and IgE sensitization to food allergens in children as well as to aeroallergens and cross-reactive plant allergen components in adults. The pathogenesis of EoE is distinct from IgE-mediated food allergy and EoE is characterized by a nonIgE-mediated food hypersensitivity \{Simon, 2016\#94\}.

\section{Prevention-treatment}

A major drawback of oral immunotherapy for food allergy is the possibility of severe side-effects. Oral immunotherapy with low allergenic hydrolysed egg (HydE) in egg allergic children was found to be safe a safe. Although not significant, HydE given for 6 months increased numerically the proportion of patients becoming tolerant to egg. HydE induced a modulation of the immune response towards better tolerance. A longer treatment period may improve the clinical outcome and should be evaluated (43).

The prevalence of peanut allergy in younger siblings of children with peanut allergy is around $8 \%$, but the anaphylactic risk at the time of introduction is currently unknown, which limits our ability to best counsel parents on this issue. A prospective, double-blinded assessment of risk, of diagnostic tests, and an analysis of patient preferences was carried out in 54 peanut-naive younger siblings of peanutallergic children (44). There is an increased risk of anaphylaxis upon peanut introduction in siblings of children with peanut allergy, and parents are reluctant to introduce at home without testing. Allergy testing prior to introduction is negative in over $90 \%$ of cases and carries a high negative predictive value.

Oral immunotherapy for peanut allergy was found to induce eosinophilic esophagitis in three children (45)

This article is protected by copyright. All rights reserved. 
Anti-IgE-assisted desensitization to egg and cow's milk may be an alternative in patients refractory to conventional OIT (46)

Nonessential allergy diets in children with mild symptoms may harm the development of immunological tolerance and impose a burden on families and day care. One of the goals of the Finnish Allergy Programme was to reduce the burden of allergy diets in Finnish day care by change in practices (47). This national programme (48) supported by the European Innovation Partnership on Active and Healthy Ageing (49) developed a new special diet form and an information leaflet based on the new allergy guidelines. The new form was implemented into 40 Finnish day care centres in 2013-2015. After 2 years, the new special diet form was used by $64 \%$ of families with food-allergic children, and the prevalence of allergy diets in day care centres decreased by $43 \%$ to $4.3 \%$. The new practice was well accepted by day care and kitchen personnel. Lack of updated allergy knowledge was noted among day care personnel indicating the need for continuous education.

Adolescents with food allergy have poorer psychosocial outcomes compared with their nonallergic counterparts. Healthcare professionals should seek adolescent and parental perspectives when assessing emotional and behavioral problems and monitor mental health during the transition to adulthood (50). Families with food allergy are at risk of reduced HRQL and elevated anxiety. A moderate level of anxiety may be beneficial to sustain vigilance for food avoidance; however, excessive anxiety may increase risk for burden and maladjustment. Families with food allergy were characterized by patterns of food allergy management, anxiety, and ability to integrate food allergy demands into daily life. Identified adaptation patterns correspond with clinical impressions and provide a framework for identifying families in need of intervention (51).

\section{Abbreviations}

AD: Atopic dermatitis

ALLADIN: Assessment of Lifestyle and Allergic Disease During Infancy

AR: Allergic rhinitis

Ara h 2: Arachis hypogaea allergen 2

Bet v 1: Betula verucosa allergen 1

ßLg: B-lactoglobulin

CD: Cluster Differentiation

CMA: Cow's milk allergy

Cor a 14: Corylus avelana allergen 14

CRD: Component resolved diagnosis

DBPCFC: Double blind placebo controlled food challenge

EAACI: European Academy of Allergy and Clinical Immunology

EoE: Eosinophilic esophagitis

FLG: Fillagrin

FoxP3: forkhead box P3

Gly m 4 : Glycine max allergen 4

HRQL: health-related quality of life

IDO : Indoleamine 2,3-dioxygenase

IL: Interleukin

Mal d 1: Malus domestica allergen 1

OFC: Oral food challenge

OIT: Oral immunotherapy

PUFAs: Polyunsaturated fatty acids

SNIP: single nucleotide polymorphisms

This article is protected by copyright. All rights reserved. 
SPT: Skin prick test

TGF- $\beta$ : Transforming Growth Factor $\beta$

TLR6: Toll-like receptor 6

Treg: T regulatory cell

TSLP: Thymic stromal lymphopoietin

\section{References}

1. Tomazic PV, Graessel A, Silva D, Eguiluz-Gracia I, Guibas GV, Grattan C, et al. A mutually beneficial collaboration between the European Academy of Allergy and Clinical Immunology Junior Members and Clinical and Translational Allergy. Clin Transl Allergy. 2016;6:43.

2. Muraro A, Fokkens WJ, Pietikainen S, Borrelli D, Agache I, Bousquet J, et al. European Symposium on Precision Medicine in Allergy and Airways Diseases: Report of the European Union Parliament Symposium (October 14, 2015). Allergy. 2016;71(5):583-7.

3. Bogh KL, van Bilsen J, Glogowski R, Lopez-Exposito I, Bouchaud G, Blanchard C, et al. Current challenges facing the assessment of the allergenic capacity of food allergens in animal models. Clin Transl Allergy. 2016;6:21.

4. Bouchaud G, Castan L, Chesne J, Braza F, Aubert P, Neunlist M, et al. Maternal exposure to GOS/inulin mixture prevents food allergies and promotes tolerance in offspring in mice. Allergy. 2016;71(1):68-76.

5. Kobayashi Y, Akiyama H, Huge J, Kubota H, Chikazawa S, Satoh T, et al. Fish collagen is an important panallergen in the Japanese population. Allergy. 2016;71(5):720-3.

6. Uotila R, Kukkonen AK, Pelkonen AS, Makela MJ. Cross-sensitization profiles of edible nuts in a birch-endemic area. Allergy. 2016;71(4):514-21.

7. Brandstrom J, Lilja G, Nilsson C, Ingemarsson N, Borres MP, Brostedt P, et al. IgE to novel citrus seed allergens among cashew-allergic children. Pediatr Allergy Immunol. 2016;27(5):550-3.

8. Kuehn A, Codreanu-Morel F, Lehners-Weber C, Doyen V, Gomez-Andre SA, Bienvenu F, et al. Cross-reactivity to fish and chicken meat - a new clinical syndrome. Allergy. 2016;71(12):1772-81.

9. Ballmer-Weber BK, Brockow K, Fiocchi A, Theler B, Vogel L, Ring J, et al. Hydrolysed egg displays strong decrease in allergenicity and is well tolerated by egg-allergic patients. Allergy. 2016;71(5):728-32.

10. Miceli Sopo S, Greco M, Cuomo B, Bianchi A, Liotti L, Monaco S, et al. Matrix effect on baked egg tolerance in children with IgE-mediated hen's egg allergy. Pediatr Allergy Immunol. 2016;27(5):465-70.

11. Mastrorilli C, Tripodi S, Caffarelli C, Perna S, Di Rienzo-Businco A, Sfika I, et al. Endotypes of pollen-food syndrome in children with seasonal allergic rhinoconjunctivitis: a molecular classification. Allergy. 2016;71(8):1181-91.

12. Buyuktiryaki B, Sahiner UM, Girgin G, Birben E, Soyer OU, Cavkaytar O, et al. Low indoleamine 2,3-dioxygenase activity in persistent food allergy in children. Allergy. 2016;71(2):258-66.

13. Pastor-Vargas C, Maroto AS, Diaz-Perales A, Villalba M, Esteban V, Ruiz-Ramos M, et al. Detection of major food allergens in amniotic fluid: initial allergenic encounter during pregnancy. Pediatr Allergy Immunol. 2016;27(7):716-20.

14. Henneman P, Petrus NCM, Venema A, van Sinderen F, van der Lip K, Hennekam RC, et al. Genetic susceptibility for cow's milk allergy in Dutch children: the start of the allergic march? Clin Transl Allergy. 2015;6:7.

15. Melnik BC, John SM, Carrera-Bastos P, Schmitz G. Milk: a postnatal imprinting system stabilizing FoxP3 expression and regulatory T cell differentiation. Clin Transl Allergy. 2016;6:18.

This article is protected by copyright. All rights reserved. 
16. Ueno HM, Kato T, Ohnishi H, Kawamoto N, Kato Z, Kaneko H, et al. T-cell epitope-containing hypoallergenic beta-lactoglobulin for oral immunotherapy in milk allergy. Pediatr Allergy Immunol. 2016;27(8):818-24.

17. Chauveau A, Nguyen-Grosjean VM, Jacquenet S, Richard C, Mouton-Faivre C. Immediate hypersensitivity to extensively hydrolyzed formulas: An important reminder. Pediatr Allergy Immunol. 2016;27(5):541-3.

18. Schocker F, Baumert J, Kull S, Petersen A, Becker WM, Jappe U. Prospective investigation on the transfer of Ara h 2, the most potent peanut allergen, in human breast milk. Pediatr Allergy Immunol. 2016;27(4):348-55.

19. Rosenlund H, Fagerstedt S, Alm J, Mie A. Breastmilk fatty acids in relation to sensitization - the ALADDIN birth cohort. Allergy. 2016;71(10):1444-52.

20. Virta LJ, Kautiainen H, Kolho KL. Symptoms suggestive of cow's milk allergy in infancy and pediatric inflammatory bowel disease. Pediatr Allergy Immunol. 2016;27(4):361-7.

21. Protudjer JL, Jansson SA, Middelveld R, Ostblom E, Dahlen SE, Arnlind MH, et al. Impaired health-related quality of life in adolescents with allergy to staple foods. Clin Transl Allergy. 2016;6:37.

22. Maslin K, Dean T, Arshad SH, Venter C. Dietary variety and food group consumption in children consuming a cows' milk exclusion diet. Pediatr Allergy Immunol. 2016;27(5):471-7.

23. Maslin K, Oliver EM, Scally KS, Atkinson J, Foote K, Venter C, et al. Nutritional adequacy of a cows' milk exclusion diet in infancy. Clin Transl Allergy. 2016;6:20.

24. Mahesh PA, Wong GW, Ogorodova L, Potts J, Leung TF, Fedorova O, et al. Prevalence of food sensitization and probable food allergy among adults in India: the EuroPrevall INCO study. Allergy. 2016;71(7):1010-9.

25. Venter C, Maslin K, Arshad SH, Patil V, Grundy J, Glasbey G, et al. Very low prevalence of IgE mediated wheat allergy and high levels of cross-sensitisation between grass and wheat in a UK birth cohort. Clin Transl Allergy. 2016;6:22.

26. Haktanir Abul M, Dereci S, Hacisalihoglu S, Orhan F. Is kiwifruit allergy a matter in kiwifruitcultivating regions? A population-based study. Pediatr Allergy Immunol. 2017;28(1):38-43.

27. Gray CL, Levin ME, du Toit G. Egg sensitization, allergy and component patterns in African children with atopic dermatitis. Pediatr Allergy Immunol. 2016;27(7):709-15.

28. Luyt DK, Vaughan D, Oyewole E, Stiefel G. Ethnic differences in prevalence of cashew nut, pistachio nut and almond allergy. Pediatr Allergy Immunol. 2016;27(6):651-4.

29. Strom MA, Silverberg JI. Asthma, hay fever, and food allergy are associated with caregiver-reported speech disorders in US children. Pediatr Allergy Immunol. 2016;27(6):604-11.

30. Eller E, Mortz CG, Bindslev-Jensen C. Cor a 14 is the superior serological marker for hazelnut allergy in children, independent of concomitant peanut allergy. Allergy. 2016;71(4):556-62.

31. Segura N, Abos T, Compaired JA, Compes E, Guallar I, Morales M, et al. Influence of profilin on sensitisation profiles determined by cutaneous tests and IgE to major allergens in polysensitised patients. Clin Transl Allergy. 2016;6:23.

32. Kinaciyan T, Nagl B, Faustmann S, Kopp S, Wolkersdorfer M, Bohle B. Recombinant Mal d 1 facilitates sublingual challenge tests of birch pollen-allergic patients with apple allergy. Allergy. 2016;71(2):272-4.

33. Treudler R, Franke A, Schmiedeknecht A, Ballmer-Weber BK, Worm M, Werfel T, et al. Standardization of double blind placebo controlled food challenge with soy within a multicentre trial. Clin Transl Allergy. 2016;6:39.

34. Saleh-Langenberg J, Flokstra-de Blok BM, AlAgla N, Kollen BJ, Dubois AE. Late reactions in food-allergic children and adolescents after double-blind, placebo-controlled food challenges. Allergy. 2016;71(7):1069-73.

This article is protected by copyright. All rights reserved. 
35. Furuya K, Nagao M, Sato Y, Ito S, Fujisawa T, investigators IPg. Predictive values of egg-specific IgE by two commonly used assay systems for the diagnosis of egg allergy in young children: a prospective multicenter study. Allergy. 2016;71(10):1435-43.

36. van der Valk JP, Gerth van Wijk R, Flokstra-de Blok BM, van der Velde JL, de Groot H, Wichers HJ, et al. No difference in health-related quality of life, after a food challenge with cashew nut in children participating in a clinical trial. Pediatr Allergy Immunol. 2016;27(8):812-7.

37. Santos AF, Becares N, Stephens A, Turcanu V, Lack G. The expression of CD123 can decrease with basophil activation: implications for the gating strategy of the basophil activation test. Clin Transl Allergy. 2016;6:11.

38. Santos AF, Lack G. Basophil activation test: food challenge in a test tube or specialist research tool? Clin Transl Allergy. 2016;6:10.

39. Lotzsch B, Dolle S, Vieths S, Worm M. Exploratory analysis of CD63 and CD203c expression in basophils from hazelnut sensitized and allergic individuals. Clin Transl Allergy. 2016;6:45.

40. Holvoet S, Doucet-Ladeveze R, Perrot M, Barretto C, Nutten S, Blanchard C. Beneficial effect of Lactococcus lactis NCC 2287 in a murine model of eosinophilic esophagitis. Allergy. 2016;71(12):1753-61.

41. Muir AB, Benitez AJ, Dods K, Spergel JM, Fillon SA. Microbiome and its impact on gastrointestinal atopy. Allergy. 2016;71(9):1256-63.

42. Straumann A, Blanchard C, Radonjic-Hoesli S, Bussmann C, Hruz P, Safroneeva E, et al. A new eosinophilic esophagitis (EoE)-like disease without tissue eosinophilia found in EoE families. Allergy. 2016;71(6):889-900.

43. Giavi S, Vissers YM, Muraro A, Lauener R, Konstantinopoulos AP, Mercenier A, et al. Oral immunotherapy with low allergenic hydrolysed egg in egg allergic children. Allergy. 2016;71(11):1575-84.

44. Begin P, Graham F, Killer K, Paradis J, Paradis L, Des Roches A. Introduction of peanuts in younger siblings of children with peanut allergy: a prospective, double-blinded assessment of risk, of diagnostic tests, and an analysis of patient preferences. Allergy. 2016;71(12):1762-71.

45. Semancik E, Sayej WN. Oral immunotherapy for peanut allergy induces eosinophilic esophagitis: three pediatric case reports. Pediatr Allergy Immunol. 2016;27(5):539-41.

46. Martorell-Calatayud C, Michavila-Gomez A, Martorell-Aragones A, Molini-Menchon N, Cerda-Mir JC, Felix-Toledo R, et al. Anti-IgE-assisted desensitization to egg and cow's milk in patients refractory to conventional oral immunotherapy. Pediatr Allergy Immunol. 2016;27(5):544-6.

47. Erkkola M, Saloheimo T, Hauta-Alus H, Kukkonen AK, Virta S, Kronberg-Kippila C, et al. Burden of allergy diets in Finnish day care reduced by change in practices. Allergy. 2016;71(10):1453-60.

48. Haahtela T, Valovirta E, Bousquet J, Makela M, and the Allergy Programme Steering G. The Finnish Allergy Programme 2008-2018 works. Eur Respir J. 2017;49(6).

49. Bousquet J, Farrell J, Crooks G, Hellings P, Bel EH, Bewick M, et al. Scaling up strategies of the chronic respiratory disease programme of the European Innovation Partnership on Active and Healthy Ageing (Action Plan B3: Area 5). Clin Transl Allergy. 2016;6:29.

50. Ferro MA, Van Lieshout RJ, Ohayon J, Scott JG. Emotional and behavioral problems in adolescents and young adults with food allergy. Allergy. 2016;71(4):532-40.

51. Fedele DA, McQuaid EL, Faino A, Strand M, Cohen S, Robinson J, et al. Patterns of adaptation to children's food allergies. Allergy. 2016;71(4):505-13.

This article is protected by copyright. All rights reserved. 